\title{
ARAŞTIRMA / RESEARCH \\ PCR-SSP tekniğine dayalı laboratuvar yapımı HLA-B*27 optimizasyonu ve test kiti geliştirilmesi
}

\author{
In-house HLA-B*27 optimization and test kit development based on PCR-SSP \\ technique
}

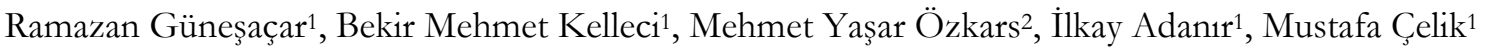

${ }^{1}$ Kahramanmaraș Sütçü İmam Üniversitesi Tıp Fakültesi, Tıbbi Biyoloji Anabilim Dalı Doku Tipleme Laboratuvarı, ${ }^{2}$ Çocuk Sağlığı ve Hastalıkları Anabilim Dalı, Çocuk İmmünoloji ve Alerji Hastalıkları Bilim Dalı, Kahramanmaraş, Turkey

\begin{abstract}
Purpose: In the present study, we aimed to develop a reliable, cost effective and suitable for routine use in-house HLA-B*27 PCR-SSP typing kit for the molecular diagnosis of Ankylosing spondylitis and other
\end{abstract} spondyloarthropathies.

Materials and Methods: The study included 565 cases with 446 negative and 119 positive HLA-B*27 subjects. PCR optimization was performed for HLA-B*27 alleles using sequence-specific and internal control primers designed based on HLA-B and beta globin gene sequences, respectively.

Results: The presence of 149 bp specific band with 273 bp internal control band showed $\mathrm{B}^{*} 27$ positivity and the presence of only 273 bp control band showed $\mathrm{B} * 27$ negativity on $2.0 \%$ agarose gel. The HLA-B*27 results show $100 \%$ sensitivity and specificity to our in-house SSP kit developted by our laboratory and the commercially available SSP kits. The cost of the in-house PCR-SSP kit we developed was at least 50 times cheaper than the commercial kits. In addition to the faultless correlation between the kits, our in-house SSP kit did not cross-react with other HLA-B alleles such as $\mathrm{B}^{*} 07, \mathrm{~B} * 12, \mathrm{~B}^{* 13}, \mathrm{~B} * 16$, $\mathrm{B}^{*} 17, \mathrm{~B}^{*} 22, \mathrm{~B}^{*} 37, \mathrm{~B}^{*} 40, \mathrm{~B}^{*} 41, \mathrm{~B}^{*} 42, \mathrm{~B}^{*} 47$ and $\mathrm{B} * 48$.

Conclusion: The fully evaluated findings show that inhouse SSP kit for HLA-B*27 typing we developed is reliable, cost effective and suitable for routine use in tissue typing and genetic laboratories.

Key words: HLA-B*27, PCR-SSP, Test kit development, Ankylosing spondylitis, Spondyloarthropathies
Öz

Amaç: Çalışmada Ankilozan spondilit ve diğer spondiloartropatilerin moleküler tanısında kullanılmak üzere güvenilir, ekonomik ve rutin kullanıma uygun laboratuvar yapimı (in-house) HLA-B*27 PCR-SSP tanı kiti geliştirilmesi amaçlanmıştır.

Gereç ve Yöntem: Çalışmaya, ticari kitler kullanılarak HLA-B*27 pozitif olarak saptanan 119 ve negatif olarak saptanan 446 olmak üzere toplam 565 olgu dahil edildi. HLA-B*27 tipleme için sekansa spesifik primerler ve beta globin gen bölgesinden yararlanılarak dizayn edilen internal kontrol primer çifti kullanılarak PCR optimizasyonu gerçekleştirildi.

Bulgular: HLA-B*27'si pozitif olan olgularda, \%2'lik agaroz jelinde 273 bç internal kontrol bandının ilerisinde 149 bç'lik spesifik bant olmak üzere çift bant, B*27 negatif hastalarda ise sadece 273 bç'lik internal kontrol bandı saptand1. 'Ticari kitler kullanılarak HLA-B*27'si pozitif olarak saptanan 119 ve negatif olarak saptanan 446 bireyin sonuçları ile tarafımızdan geliştirilen PCR-SSP kiti kullanılarak elde edilen sonuçların tamamen uyumlu olması nedeniyle sensitivite ve spesifite \%100 olarak belirlendi. Geliştirdiğimiz laboratuvar yapımı PCR-SSP kitinin maliyetinin, ticari kitlere göre en az 50 kat daha ucuz olduğu görüldü.

Sonuç: Ticari kitler kullanılarak HLA-B*27'si pozitif olarak saptanan 119 ve negatif olarak saptanan 446 olgunun tamamında, geliştirdiğimiz yöntemle de birebir uyumlu sonuçlar elde edildi. Bu bulgular geliştirdiğimiz kitin güvenilir, ekonomik ve rutin kullanıma uygun olduğunu göstermektedir.

Anahtar kelimeler: HLA-B*27, PCR-SSP, Test kiti geliştirilmesi, Ankilozan spondilit, Spondiloartropatiler

Yazışma Adresi/Address for Correspondence: Dr. Ramazan Güneşaçar, Kahramanmaraş Sütçü İmam Üniversitesi Tıp Fakültesi, Tıbbi Biyoloji Anabilim Dalı, Doku Tipleme Laboratuvar1, E-mail: rgunesacar@hotmail.com

Geliş tarihi/Received: 2.6.2018 Kabul tarihi/Accepted: 31.7.2018 Published online: 15.9.2018 


\section{GİRİŞ}

İnsan lökosit antijenleri (Human Leukocyte Antigens, HLA) büyük doku uygunluk kompleksi (Major Histocompatibility Complex, MHC) genleri tarafindan eksprese edilmektedir. MHC lokusu 6. kromozomun kısa kolunda (6p 21.3) yerleşik olup, sinıf 1, sinif 2 ve sinif 3 genlerini kapsamaktadır. Bunlardan klasik Sinıf 1 MHC antijenleri HLA-A, B ve $C$ olarak isimlendirilmekte ve hemen hemen nükleusa sahip bütün hücrelerde bulunmakla birlikte en fazla trombositlerde eksprese edilmektedirler. HLA-E, F, G antijenleri ise non-klasik sinıf $1 \mathrm{MHC}$ antijenleridir, sınırlı sayıda dokuda eksprese olurlar. Benzer olarak, klasik sınıf 2 MHC antijenleri HLA$\mathrm{DR}$, DP ve DQ olarak isimlendirilmektedir. $\mathrm{Bu}$ moleküller B lenfosit, aktive $\mathrm{T}$ lenfosit, makrofaj, dendritik hücre ve langerhans hücrelerinde eksprese edilirler. MHC sinıf 3 gen bölgesi ise HLA antijenleri ile ilişkisi bulunmayan bazı kompleman komponentleri (C2, C4, faktör B) ile bazı sitokinler (tümör nekroz faktör alfa ve beta, interferon), bazı 1s1 şoku proteinleri ve bazı enzimleri (21 hidroksilaz) kodlamaktadır ${ }^{1}$. MHC gen bölgesinin her lokusunda her biri farklı HLA antijenlerini kodlayan allel genler bulunur. MHC, insanda bilinen en polimorfik gen bölgesi olup, Mayıs 2018 itibariyle sinıf 1 alleleri sayıs1 13.324, sinif 2 alleleri sayıs ise $4.857^{\prime} \mathrm{dir}^{2}$.

Oldukça polimorfik olan HLA-B*27, 1969 yilında Thorsby tarafindan tanımlanmıştır ${ }^{3}$. HLA-B*27 geni 6. kromozomun k1sa kolunda (6p21.3) bulunmakta olup 4287 baz çiftinden ibarettir. HLA-B*27 geni bir TATA, bir poly-A ve 4 adet alternatif kesip ekleme sinyallerine ek olarak, 7 ekzon ve 6 intron içermektedir. Bu genin ürünü olan protein, 15. kromozom tarafindan kodlanan bir $\beta 2$ mikroglobulin zinciri ile bağlantılı üç adet $\alpha$ zincirinden oluşmuştur ve toplam 362 amino asitten ibarettir. Ekzon 1 lider peptidi, ekzon 2 ve ekzon 3 $\alpha 1$ ve $\alpha 2$ bölgelerini, ekzon $4 \alpha 3$ bölgesini, ekzon 5 transmembran bölgesini, ekzon 6 ve 7 ise sitoplazmik kuyruğu kodlamaktadır. Bu protein tüm HLA sinıf I moleküllerinde korunmuş olan $\alpha 3$ zinciri ve bir transmembran bölgesi ile bir sitoplazmik kuyruğa sahiptir. Molekülün oldukça polimorfik olan peptid bağlama bölgesi $\alpha 1$ ve $\alpha 2$ zincirleri arasında bulunmaktadır. Peptid bağlama bölgesi A-F olarak adlandirılan altı adet cep tarafindan oluşturulmuştur. Bunlardan $A$ ve $F$ cepleri, peptitin amino ve karboksil uçlarıyla etkileşime girdiklerinden, bu ceplerdeki polimorfik rezidüler çeşitli HLA alleleri için farklı peptitlerin bağlanmasını sağladıklarından hastalıklara yatkınlığa neden olmaktadır ${ }^{4}$.

HLA allelleri antropolojik araştırmalar ve adli tıp olaylarında da kullanılmakla birlikte en önemli kullanım alanı organ ve doku nakillerinde alıcı ve verici arasındaki doku tipinin belirlenmesidir. Son yıllarda üzerinde en çok araştırma yapılan konu ise HLA allellerinin hastalıklarla olan ilişkisidir. Belirli HLA tipleri ile bazı hastalıklar arasında yüksek oranda ilişki olduğu gösterilmiştir. Bunlardan en iyi bilineni ise 1973 yllında Brewerton ve arkadaşları tarafindan tanımlanmış olan HLA-B*27 geni ile ankilozan spondilit (AS) arasındaki ilişkidir ${ }^{5}$. HLAB*27'nin reaktif artrit, jüvenil romatoid artrit ve anterior üveit gibi diğer spondiloartropatiler için de genetik risk faktörü olduğu bilinmektedir ${ }^{6}$. AS etyolojisi bilinmeyen, spinal eklemlerde ve bu eklemlerin çevresinde belirgin inflamasyon ile karakterize sistemik bir hastalıktır. Hastalık genellikle adelosan çağda ya da 20’li yaşlarda başlamakla birlikte, çocukluk çağında ya da ileri yaşlarda da başlayabilmekte ve erkeklerde kadınlara oranla daha sık (3:1.8) görülmektedir7. Yapılan çalışmalarda AS hastalarının \%90-95'inde HLA-B*27 pozitifliği saptanmıştır. AS'li hastaların HLA-B*27'si pozitif olan birinci derece yakınlarında hastalık riski 3 kat $\operatorname{artmaktadir}^{8-11}$.

AS'li hastaların \%90'1 HLA-B*27 alleli taşımakla birlikte, bu allelin AS'nin patogenezi ve prognozu üzerine etkisi henüz tam olarak anlaşılamamıştır. Bir Sınıf I MHC molekülü olan HLA-B27, endojen antijenik peptitlerin sitotoksik $\mathrm{T}$ hücrelerinin (CD8+) yüzeyindeki reseptörlere (TCR) sunulmasinda önemli bir rol oynamakta ve immün sistemin aktivasyonuna aracillk etmektedir. Ayrıca, HLA-B27 ve diğer HLA sınıf I moleküllerinin, doğal öldürücü (NK) hücrelerin yüzeyinde bulunan immünoglobulin benzeri reseptörlere (KIR) bağlanarak doğal immün yanıta (innate immunity) aracilık ettiği de gösterilmiştir ${ }^{12-14}$.

HLA-B27 molekülünün hangi özelliklerinin AS'ye yatkınlık için temel rol oynadığ1 sorusuna cevap olarak birkaç hipotez sunulmuştur. Bunların içerisinde en çok kabul gören artritogenik peptit hipotezine göre, AS ile ilişkili HLA-B*27 molekülü iç (self) ya da dış kaynaklı (bazı bakteriler) antijenik peptidlere bağlanarak, HLA-B*27 ile sinırlı sitotoksik $\mathrm{T}$ hücre aktivasyonu ve immün reaksiyonlar1 takiben AS'ye neden olabilmektedir ${ }^{15-}$

18. Bununla birlikte, HLA-B27 molekülünün tüm alt 
tiplerine bağlanma özelliği gösteren AS ile ilişkili bir peptit bulunamamıştır ${ }^{19}$.

Araştırmalar, HLA-B genindeki nükleotid dizi farklılıklarının çeşitli HLA-B*27 alleleri arasında yapısal ve fonksiyonel değişikliklere yol açtı̆̆ını göstermektedir. Örneğin, HLAB*27:05 ve HLA$\mathrm{B} * 27: 09$ alleleri arasinda tek bir amino asit fark1 vardır (B*27:05'de molekülün 116. pozisyonda aspartik asit, $\mathrm{B} * 27: 09$ 'da histidin bulunmaktadir). Bir tek amino asit farkı bu allelerin AS ile ilişkisinin tamamen değişmesine yol açmaktadır. Yani, HLAB27:09 AS ile ilişkisiz ya da zayıf ilişkili iken, HLA$B * 27: 05$ alleli hastalığa yatkınlık oluşturmaktadır. Benzer durum HLA-B*27:04 ve HLA-B*27:06 alleleri arasında da bulunmaktadir ${ }^{20,21}$.

HLA-B*27 geninin bugün için bilinen 223 varyantı mevcut olup

(https://www.ebi.ac.uk/ipd/imgt/hla/allele.html) bu varyasyonların bazıları protein üzerinde etkisizdir. Bundan dolayı her ne kadar 223 farklı genetik varyant bulunsa da sentezlenen proteinde bir veya birkaç amino asitin farklı olması HLA-B*27'nin 167 alt tipinin (HLA-B*27:01 - HLA-B*27:167) ortaya çıkmasını sağlamıştır ${ }^{22,23}$. Bu alt tipler arasında en yaygin görülen allel tipi $\mathrm{B}^{* 27: 05}$ 'dir ve tüm etnik gruplarda bulunmaktadır 2,24,25. HLA-B*27 allel tipleri frekansı populasyonlar arasında oldukça değişiklik göstermektedir. Dünya çapında yapılan populasyon tabanlı çalıșmalarda HLA-B*27:02, $\mathrm{B} * 27: 04$ ve $B * 27: 05$ allellerinin AS ile güçü bir birliktelik gösterdiği saptanmıştır ${ }^{25-27}$. $\mathrm{Bu}$ allellerden B*27:02'nin Akdeniz populasyonlarında, B*27:04'ün Asyalılarda, $B^{*} 27: 05$ 'in ise Kafkaslar ve Amerikan Yerlilerinde yaygin olduğu gösterilmiştir ${ }^{28}$. Ülkemizde yapılan çalışmalarda ise HLA-B*27 sıklı̆gının \% 2.6, en sik görülen allellerin HLA$B * 27: 05$ ve $B * 27: 02$, şimdiye kadar gösterilen HLA$\mathrm{B} * 27$ allelerinin ise $\mathrm{B} * 27: 02,28: 04,27: 05,27: 07$, 27:08 ve çok nadir olarak da 27:46, 27:49 ile 27:67 olduğu belirlenmiştir ${ }^{29-32}$. Buna karşın HLA-B*27:07 allelinin AS’ye karş1 koruyucu olduğu yani $B * 27: 07$ allelini taşıyanların AS'den korunduğu ve bu allelin sadece sağllklı bireylerde bulunduğu gösterilmiştir ${ }^{33}$. Diğer yandan, HLA-B*27:06 ve 27:09'un AS ile ilişkisiz ya da zayıf ilişkili olduğu bildirilmiştir ${ }^{34,35}$.

HLA-B*27 PCR-SSP kiti ankilozan spondilit ve diğer spondiloartropatilerin moleküler tanısı için ülkemizdeki doku tipleme ve/veya genetik laboratuvarlarında en sik kullanılan kitlerden birisi olup ithal edilmekte ve ülkemiz için mali bir yük oluşturmaktadır. Bu nedenle, çalışmamızda doku tipleme ve genetik laboratuvarlarında AS ve diğer spondiloartropatilerin moleküler tanısında kullanılmak üzere HLA-B*27 allelerinin hemen hemen tamamını tek tüpte belirleyebilen, güvenilir, ekonomik ve rutin kullanıma uygun laboratuvar yapımı (in-house) PCR-SSP tanı kiti geliştirilmesi amaçlanmıştır.

\section{GEREÇ VE YÖNTEM}

\section{Kan ve DNA örneklerinin sağlanması}

Çalışmaya Kahramanmaraş Sütçü İmam Üniversitesi Sağlık Uygulama ve Araştırma Hastanesinin çeşitli birimlerinden HLA-B*27 istemiyle ya da organ nakli için laboratuvarımıza doku tipleme testinin belirlenmesi istemiyle yönlendirilen olgulardan PCRSSP düşük çözünürlüklü ticari kitler (DIAGEN Biyolojik Sistemler A.Ş., Türkiye, One Lambda Inc., CA, USA, Inno-Train, Germany) kullanılarak HLAB*27 alleli pozitif olarak saptanan 119 , negatif olarak saptanan 446 olmak üzere toplam 565 olgu dahil edildi. HLA-B*27 alleli negatif olarak saptanan 446 olgunun 12'si ise daha önce doku tipleme amaciyla laboratuvarımıza yönlendirilen ve ticari kitler (One Lambda Inc., CA, USA, Inno-train, Germany) kullanılarak HLA-A*, B* ve DRB1* allelleri çalışılan ve HLA-B*27 alleli ile çapraz reaksiyon verdiği bilinen HLA-B grubu allelere sahip transplant hastaları ya da donörlerden seçildi. Kahramanmaraș Sütçü İmam Üniversitesi Tip Fakültesi Klinik Araştırmalar Etik Kurulu'ndan çalışmaya dair etik kurul onayı alındı (tarih: 04.04.2018, oturum: 2018/07, karar no: 003 ).

\section{DNA ekstraksiyonu}

DNA ekstraksiyonu için Miller ve arkadaşlarının salting out yöntemi ${ }^{36}$ laboratuvar şartlarımıza göre modifiye edilerek uygulandi. DNA konsantrasyonunun belirlenmesi için $1 \mathrm{ml}$ hacimli iki adet quartz tüp alındı. Bunlardan blank olarak kullanılacak olan 1. tüpe $1000 \mu \mathrm{l}$, ikinci tüpe ise 990 $\mu \mathrm{l}$ steril bidistile $\mathrm{H}_{2} \mathrm{O}$ konuldu. İkinci tüpe ekstrakte edilen genomik DNA'dan $10 \mu$ l konulup iyice pipetlenerek homojen hale getirildi. Her iki tüp spektrofotometrede (Shimadzu, Japan) 260 ve 280 nm dalga boyunda ayr1 ayr1 okunduktan sonra DNA konsantrasyonu ve DNA'nın saflığı hesaplandı. Elde edilen genomik DNA konsantrasyonları 20-50 ng/ $\mu \mathrm{l}$ olacak şekilde ayarlandıktan sonra çalışma gününe kadar $-20^{\circ} \mathrm{C}$ 'de muhafaza edildi. 


\section{PCR-SSP}

HLA-B geninin DNA dizisi temel alınarak dizayn edilen sense ve antisense primerler ${ }^{37}$ ile beta globin (HBB) gen bölgesinden yararlanılarak dizayn edilen internal kontrol primer çifti Tablo 1'de verilmiştir.

Tablo 1. HLA-B*27 ve internal kontrol (HBB) primer dizileri

\begin{tabular}{|l|l|}
\hline $\begin{array}{l}\text { Sense/Antisense } \\
\text { Primer }\end{array}$ & Nükleotit Dizisi \\
\hline $\begin{array}{l}\text { HLA-B*27 Sense } \\
\text { primer }\end{array}$ & $\begin{array}{l}\text { 5'-GCT ACG TGG ACG } \\
\text { ACA CGC T-3' }\end{array}$ \\
\hline $\begin{array}{l}\text { HLA-B*27 Antisense } \\
\text { primer 1 }\end{array}$ & $\begin{array}{l}\text { 5'-CTC GGT CAG TCT } \\
\text { GTG CCT T-3' }\end{array}$ \\
\hline $\begin{array}{l}\text { HLA-B*27 Antisense } \\
\text { primer 2 }\end{array}$ & $\begin{array}{l}\text { 5'-TCT CGG TAA GTC } \\
\text { TGT GCC TT3' }\end{array}$ \\
\hline HBB Sense primer & $\begin{array}{l}\text { 5'-CCA GAA GAG CCA } \\
\text { AGG ACA GGT ACG-3' }\end{array}$ \\
\hline HBB Antisense primer & $\begin{array}{l}\text { 5'-AC CAA CTT CAT CCA } \\
\text { CGT TCA CC T-3' }\end{array}$ \\
\hline
\end{tabular}

HLA: Human Leukocyte Antigens, HBB: Hemoglobin Beta

Tablo 2. Amplifikasyon sıcaklık ve süreleri

\begin{tabular}{|l|c|c|c|}
\hline Aşama & $\begin{array}{c}\text { S1cakl1k } \\
\left({ }^{\circ} \mathbf{C}\right)\end{array}$ & $\begin{array}{c}\text { Süre } \\
\text { (Saniye) }\end{array}$ & $\begin{array}{c}\text { Döngü } \\
\text { Sayis1 }\end{array}$ \\
\hline 1 & 96 & $130 \mathrm{sn}$. & 1 \\
\hline 2 & 63 & $60 \mathrm{sn}$ & \\
\hline 1 & 96 & $10 \mathrm{sn}$. & 9 \\
\hline 2 & 63 & $60 \mathrm{sn}$ & \\
\hline 1 & 96 & $10 \mathrm{sn}$. & \\
\hline 2 & 59 & $50 \mathrm{sn}$. & \\
\hline 3 & 72 & $30 \mathrm{sn}$. & 20 \\
\hline 1 & 4 & $\infty$ & \\
\hline
\end{tabular}

PCR reaksiyonu için 0.2 ml'lik tüpler kullanıldı ve PCR reaksiyonu şu şekilde gerçekleştirildi: Reaksiyon hacmi $10 \mu \mathrm{L}$ olacak şekilde, her bir örnek için $3.42 \mu$ deiyonize su, $1 \mu \mathrm{l} 10 \mathrm{X}$ PCR tamponu (Invitrogen, Lithuania), $2 \mathrm{mM} \mathrm{MgCl} 2$ (Invitrogen), $0.2 \mathrm{mM}$ dNTPs (Invitrogen), $\% 5$ gliserol $+0.1 \mu \mathrm{g}$ cresol red (Sigma Aldrich, Germany), her bir primerden 2.5 pmol, $20 \mathrm{ng}$ genomik DNA ve $0.5 \mathrm{U}$ hot start DNA polimeraz enzimi (Invitrogen) ilave edildi. Tüpler termal döngü cihazına (Veriti 96 Well Thermal Cycler, Applied Biosystems) yerleştirilerek Tablo 2'de verilen amplifikasyon sıcaklık ve süreleri uygulandi.

\section{Agaroz jel elektroforezi}

Agaroz jel elektroforezi Maniatis ve arkadaşlarının yöntemine göre yapıld1 ${ }^{38}$. Agaroz $1.2 \mathrm{~g}$ tartılarak 60 ml'lik bir Erlenmayere kondu, $60 \mathrm{ml}$ 0.5X TBE tamponu eklendi (\%2'lik agaroz) ve $10 \mathrm{mg} / \mathrm{ml}$ 'lik ethidium bromid'den $3 \mu$ ilave edildikten sonra mikrodalga firında kaynatıldı. Elektroforez tarakları jel dökme kabına, tabanda $1 \mathrm{~mm}$ boşluk kalacak şekilde ayarlanarak yerleştirildi ve yaklaşık $60^{\circ} \mathrm{C}$ 'ye kadar soğutulan agaroz jeli, jel kabına döküldü, donması için oda sicaklığında $20 \mathrm{dk}$. bekletildi. Taraklar dikkatlice çıkartılarak jel kabı elektroforez tankına yerleştirildi. Jeldeki açılmış olan kuyucuklara 10'ar $\mu$ l miktarlarda PCR ürünleri aplike edildi ve 15 $\mathrm{dk}$. süreyle elektrik akımı $(10 \mathrm{volt} / \mathrm{cm})$ verildikten sonra elektroforez işlemi sonlandirilarak amplifikasyon ürünleri UV 1ş1kta (Uvitec Cambridge, UK) değerlendirildi (Şekil 1).

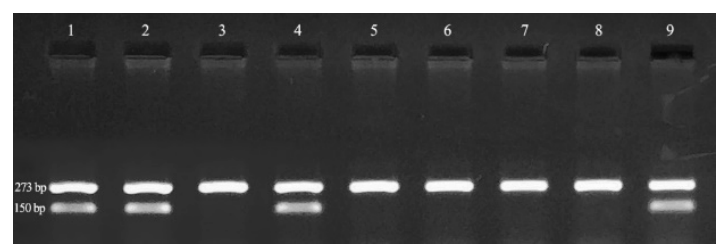

Resim 1. HLA-B*27'ye spesifik 149 bç'lik bant ile 273 bç'lik internal kontrol bandını gösteren agaroz jeli görüntüsü

(1, 2, 4 ve 9. siradaki bantlar HLA-B*27 pozitif; 3, 5, 6, 7 ve 8 . sıradaki bantlar ise HLA-B*27 negatif sonuçları göstermektedir)

\section{İstatistiksel analiz}

Üretilen laboratuvar yapımı kit ile ticari kitlerden elde edilen HLA-B*27 sonuçlarının uyumunun ölçülmesi için Kappa Coefficient testi uygulandı.

\section{BULGULAR}

Çalışmaya dahil edilen bireylerden, ticari kitler kullanilarak HLA-B*27'si pozitif olarak saptanan 119 ve negatif olarak saptanan 446 bireyin sonuçları ile tarafımızdan optimize edilen PCR-SSP kiti ile elde edilen sonuçların tamamen uyumlu olması nedeniyle sensitivite ve spesifite $\% 100$ olarak belirlendi. Öte yandan laboratuvar ortaminda üretttiğimiz kit ve ticari kitlerden elde edilen sonuçların uyumu istatistiksel olarak anlamlı bulunmuş olup (Kappa $=1,000 \mathrm{p}<0,001)$, pozitif ve negatiflikleri belirlemede aynı doğruluğa sahip oldukları gözlenmiştir (Tablo 3).

Ayrica HLA-ABDR ticari kiti ile HLA-B*27'si negatif olarak saptanmış, fakat HLA-B*27 antijeni ile çapraz reaksiyon veren diğer HLA-B allelerine $\left(\mathrm{B}^{*} 07, \mathrm{~B}^{*} 12, \mathrm{~B}^{*} 13, \mathrm{~B}^{*} 16, \mathrm{~B}^{*} 17, \mathrm{~B}^{*} 22, \mathrm{~B}^{*} 37, \mathrm{~B}^{*} 40\right.$, 
$\left.\mathrm{B}^{*} 41, \mathrm{~B}^{*} 42, \mathrm{~B} * 47, \mathrm{~B}^{*} 48\right)$ sahip olan olgularin HLA$\mathrm{B} * 27$ alleleri de tarafimızdan geliştirilen laboratuvar yapımı kit ile negatif olarak saptand. HLA-B*27'si pozitif olgularda \%2'lik agaroz jelinde 273 bç internal kontrol bandı ve 149 bç'lik spesifik bant olmak üzere çift bant, $\mathrm{B} * 27$ negatif olgularda ise sadece 273 bç'lik internal kontrol bandı saptand1 (Şekil 1). Geliştirdiğimiz laboratuvar yapımı PCRSSP kitinin maliyetinin, ticari kitlere göre en az 50 kat daha ekonomik olduğu görüldü.

Tablo 3. Laboratuvar yapımı PCR-SSP kit ile ticari PCR-SSP kitlerinin HLA-B*27 pozitif ve negatif allelere göre sensitivite ve spesifite dağılımı

\begin{tabular}{|c|c|c|c|c|c|}
\hline & & \multicolumn{2}{|c|}{ Laboratuvar yapımı PCR SSP kit } & & \\
\hline \multirow{3}{*}{ 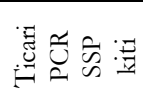 } & & Pozitif & Negatif & *Kappa katsayısı & $\mathrm{p}$ \\
\hline & Pozitif & 119 & 0 & \multirow[t]{2}{*}{1,00} & \multirow[t]{2}{*}{$\mathrm{p}<0,001$} \\
\hline & Negatif & 0 & 446 & & \\
\hline
\end{tabular}

PCR-SSP: Polymerase chain reaction-sequence specific primer; Kappa katsayıs1; $\alpha: 0,05$

Sonuçlarımızın tekrarlanabilir olduğunu göstermektedir için, farklı tarihlerde hazırlanan PCR içerikleri sekiz striptli PCR tüplerine 9'ar mikrolitre dağıtıldıktan sonra $-22{ }^{\circ} \mathrm{C}$ 'de muhafaza edildi. Çalışma günleri farklı tarihlerde hazırlanan bu tüpler derin dondurucudan alınarak oda isisinda çözündürülüp, 1'er mikrolitre genomik DNA ilave edilerek PCR ve elektroforez işlemlerini takiben UV $1 s ̧ 1 k t a$ incelendiğinde elde edilen sonuçlarda herhangi bir değişiklik gözlenmedi. Aynı işlem hot start DNA polimeraz ilaveli ve ilavesiz olarak yapıldığında da sonuçlarda herhangi bir farklılık saptanmadı.

\section{TARTIŞMA}

HLA-B27 tipleme için hücre yüzeyindeki HLA-B27 antijenini göstermeyi hedefleyen kompleman bağıml sitotoksisite $^{39,40}$ (CDC) ya da spesifik monoklonal antikorların kullanıldığı flow cytometry ${ }^{41,42}$ (FCM) yöntemleri yaygın olarak kullanılmaktadır. Canlı hücre gereksinimi, uygulanmasının zaman alması, iş yükünü artırması, pahalı ve en önemlisi de epitop benzerliğinden dolayı HLA-B27 antijeninin diğer baz1 HLA-B antijenleri (B7, B12, B13, B16, B17, B22, B37, B40, B41, B42, B47, B48) ile çapraz reaksiyon vermesi nedeniyle yanlış pozitif sonuç alma ihtimalinin yüksek olması bu yöntemlerin kullanımını sınırlamaktadır.

Ayrıca, popülasyonda çok sayıda HLA-B*27 allelerinin mevcut olmas1, dolayısıyla da tüm allelere karşı reaksiyon verecek spesifik antikor bulunmaması nedeniyle yanlış negatif sonuçlar elde etmek te mümkün olabilmektedir. Levering ve arkadaşları, ticari olarak sunulan üç farklı anti-HLAB27 monoklonal antikor klonu (ABC-m3, $n=3$; FD705; ve GS145) kullanılarak gerçekleștirdikleri HLA-B27 yüzey antijeni taramasında her üç monoklonal antikor klonunun da diğer bazı HLA-B antijenleri ile çapraz reaksiyon verdiğini, dolayısıyla da yanlış pozitif sonuçlara neden olduğunu göstermişlerdir ${ }^{43}$. Bundan dolay1, HLA-B*27 tiplendirme için SSP, SSOP, RFLP, SSCP, RT-PCR gibi PCR tabanlı birçok moleküler yöntem geliştirilmiştir. PCR-SSP bu yöntemler içinde en güvenilir ve doğrudan sonuç elde edilebilen yöntem olup doku tipleme ve genetik laboratuvarlarında s1klıkla tercih edilmektedir. PCR-SSP ilk kez Dominguez ve ark. tarafindan 1992 yılında HLAB*27 tiplemesi için uyarlanmıştır ${ }^{44}$. PCR-SSP yönteminde kullanılan primer çiftlerinden birisi HLA-B*27 alleline yani sekansa spesifik, diğer primer ise HLA-B allellerinin tamamina spesifiktir (generic primer). Çalışmamızda $B^{*} 27$ 'ye spesifik ikinci bir primer (HLA-B*27 antisense primer 2, 5'TCTCGGTAAGTCTGTGCCTT-3’) kullanilarak daha fazla sayıda HLA-B*27 allelinin tanımlanmas1 sağlanmıştır. Bununla birlikte, kullandığımız primerlerin HLA-B*27 allelerininin tamaminı tanımlamaları mümkün değildir.

PCR-SSP yöntemi uygulayarak yapılan testlerden doğru sonuç elde edilmesi yöntemin spesifitesine bağlıdır. PCR-SSP'nin spesifitesi ise kullanılan PCR tamponu, primer dizisinin GC oranı, kullanılan primerler, polimeraz ve bu enzimin kofaktörü olan $\mathrm{Mg}^{2+}$ konsantrasyonu, genomik DNA konsantrasyonu ve annealing sıcaklığı gibi birçok faktörden etkilenmektedir ${ }^{45}$. Çalışmamızda bütün bu faktörler optimize edildi. PCR reaksiyonunda kullanilan genomik DNA konsantrasyonu uygulanan dilüsyonlarla $100 \mathrm{ng} / \mu \mathrm{l}$ 'den 20ng/ $\mu$ l'ye kadar, 10 $\mathrm{ng} / \mu \mathrm{l}$ aralıklarla düşürülüp hazırlanan her bir konsantrasyon düzeyi için PCR reaksiyonu gerçekleştirildiğinde, optimum DNA konsantrasyonunun $20 \mathrm{ng} / \mu \mathrm{l}$ ila $50 \mathrm{ng} / \mu \mathrm{l}$ arasinda olduğu belirlendi. PCR reaksiyonlarında kullanılan primer çiftlerinin düşük konsantrasyonda 
kullanımının primer dimerizasyonunu önlediği bilinmektedir. Çalışmamızda başlangıçta, HLA-B*27 primerlerinin her birinin konsantrasyonu 10 pmol, internal kontrol primer çiftlerinin konsantrasyonu ise 5 pmol olarak kullanılmış ve konsantrasyon kademeli olarak düşürülmüştür. $\mathrm{Bu}$ denemeler sonunda HLA-B*27 ve internal kontrol primerlerinin konsantrasyonu 2.5 pmol'e düşürüldüğünde dimerizasyon oluşumunun minimum düzeye indiği görülmüştür. PCR reaksiyonlarında en önemli etkenler $\mathrm{Mg}^{2+}$ konsantrasyonu ve annealing sicaklığıdır. Çalışmamızda, $\mathrm{Mg}^{2+}$ konsantrasyonu ve annealing sıcaklık ve sürelerinin belirlenmesi için yapılan çeşitli denemeler sonunda, $\mathrm{Mg}^{2+}$ konsantrasyonu $2 \mathrm{mM}$, annealing sıcaklık ve süreleri ise Tablo 2 verildiği gibi uygulandığında spesifik ve oldukça belirgin bantlar elde edildi.

Farklı HLA antijenlerinin tek bir antikor tarafindan tanınması HLA antijenleri arasındaki çapraz reaksiyonlar olarak bilinmektedir. Çapraz reaksiyonlar, farklı HLA antijenlerinin aminoasit dizilerindeki ortak bölgelerden kaynaklanır. Bazı HLA antijenleri benzer epitoplara veya benzer aminoasit polimorfizmine sahip olabilmektedirler. HLA-B27 antijeni HLA-B7, B12, B13, B16, B17, B22, B37, B40, B41, B42, B47 ve B48 antijenleri ile ortak epitoplara sahip olduğu için, HLA-B27 antijeni ile reaksiyon veren antikorlar, bu HLA antijenleri ile de reaksiyon verebilmektedir ${ }^{46}$. $\mathrm{Bu}$ nedenle lenfositlerin yüzeyinde HLA-B27 ile çapraz reaksiyon veren bu antijenleri eksprese eden bireylerde HLA-B27 antijeni bulunmasa dahi CDC ya da FCM yöntemiyle yanlış pozitif sonuçlar elde edilebilmektedir. Çalıșmamızda PCR-SSP ticari kitleri ile HLA-B*27'si pozitif olarak saptanan 119 ve negatif olarak saptanan 446 olgunun tamaminda, optimize ettiğimiz yöntemle de birebir uyumlu ve aynı zamanda HLA-B*27 alleli ile çapraz reaksiyon verdiği bilinen $H L A-B * 07, B^{*} 12, B^{*} 13, B^{*} 16, B^{*} 17$, $B * 22, B * 37, B * 40, B * 41, B * 42, B * 47$ ve $B * 48$ allellerine sahip bireylerin HLA-B*27 SSP sonuçlarının negatif olarak belirlenmesi, geliştirdiğimiz kitin çapraz reaksiyonları ekarte ettiğini göstermektedir. Ayrıca, yaptığımız maliyet analizinde tarafimızdan optimize edilen laboratuvar yapımı PCR-SSP kitinin ticari kitlere göre en az 50 kat daha ucuz olduğu görüldü. Sonuçlarımız, geliştirdiğimiz kitin güvenilir, ekonomik ve rutin kullanıma uygun olduğunu bundan dolayı da doku tipleme ve/veya genetik laboratuvarlarında AS ve diğer spondiloartropatilerin tanısında güvenle kullanılabileceğini göstermektedir.

\section{Teşekkür}

Teknik desteklerinden dolay1 Bio. Mehmet Ali demir ile Laboratuvar Teknikeri Mehmet Serdar Ural'a ve istatistiksel analiz konusunda verdiği destekten ötürü Dr. Öğretim Üyesi Adem Doğaner'e teşekkür ederiz.

\section{KAYNAKLAR}

1. Schwartz BD. The human major histocompatibility HLA complex. In Basic and Clinical Immunology (Eds DP Stites, JD Stobo, JV Wells): 50-64. California, Appleton \& Lange. 1987.

2. Allele Search Tool. IMGT/HLA-IPD-EMBL-EBI. [Internet]. Available at: https://www.ebi.ac.uk/ipd/imgt/hla/stats.html

3. Thorsby E. HL-A antigens and genes. I. A study of unrelated Norwegians. Vox Sang. 1969;17:81-92.

4. Tipu HN. Mini Review: HLA B27 and its Immunogenetics in Ankylosing Spondylitis. J Genet Disor Genet Rep. 2013;2:1.

5. Brewerton DA, Hart FD, Nicholls A, Caffrey M, James DC, Sturrock RD. Ankylosing spondylitis and HL-A 27. Lancet. 1973;28:904-7.

6. Bowness P. HLA-B27 in health and disease: a double-edged sword? Rheumatology. 2002;41:85768.

7. Khan MA. Update on spondyloarthropathies. Ann Intern Med. 2002;136:896-907.

8. Seipp MT, Erali M, Wies RL, Wittwer C. HLA B27 typing: Evaluation of an allele specific PCR melting assay and two flow cytometric antigen assays. Cytometry B Clin Cytom. 2005;63:10-15.

9. Granfors K, Marker-Hermann E, de Keyser F, Khan MA, Veys EM, Yu DT. The cutting edge of spondylarthropathy research in the millennium. Arthritis Rheum. 2002;46:606-13.

10. Reveille JD, Ball EJ, Khan MA. HLA-B27 and genetic predisposing factors in spondyloarthropathies. Curr Opin Rheumatol. 2001;13:265-72.

11. Lopez-Larrea C, Gonzalez-Roces S, Alvarez V. HLA-B27 structure, function, and disease association. Curr Opin Rheumatol. 1996;8:296-308.

12. Borrego F, Masilamani M, Kabat J, Sanni TB, Coligan JE. The cell biology of the human natural killer cell CD94/NKG2A inhibitory receptor. Mol Immunol. 2005;42, 485-8.

13. Dashtia N, Mahmoudia M, Aslania S, Jamshidia A. HLA-B*27 subtypes and their implications in the pathogenesis of ankylosing spondylitis. Gene. 2018;670:15-21. 
14. Akassou A Bakri Y. Does HLA-B27 Status Influence Ankylosing Spondylitis Phenotype? Clin Med Insights Arthritis Musculoskelet Disord. 2018;11:1-6.

15. Dulphy N, Peyrat MA, Tieng V, Douay C, Rabian C, Tamouza R, et al. Common intra-articular $\mathrm{T}$ cell expansions in patients with reactive arthritis: identical $\beta$-chain junctional sequences and cytotoxicity toward HLA-B27. J Immunol. 1999;162:3830-9.

16. Fiorillo MT, Maragno M, Butler R, Dupuis ML, Sorrentino R. CD8+ T-cell autoreactivity to an HLA-B27-restricted self-epitope correlates with ankylosing spondylitis. J Clin Investig. 2000;106:4753.

17. Kuon W, Holzhütter HG, Appel H, Grolms M, Kollnberger S, Traeder A, et al. Identification of HLA-B27-restricted peptides from the Chlamydia trachomatis proteome with possible relevance to HLA-B27- associated diseases. J Immunol. 2001;167:4738-46

18. Frauendorf E, Lopez De Castro J, Märker-Hermann E. Conserved TCR $\beta$ chain usage in reactive arthritis; evidence for selection by a putative HLA-B27associated autoantigen. HLA. 2002;60:299-308.

19. Reveille JD. Major histocompatibility genes and ankylosing spondylitis. Best Pract. Res Clin Rheumatol. 2006;20:601-9.

20. Cascino I, Paladini F, Belfiore F, Cauli A, Angelini C, Fiorillo MT, Mathieu A, Sorrentino R. Identification of previously unrecognized predisposing factors for ankylosing spondylitis from analysis of HLA-B27 extended haplotypes in Sardinia. Arthritis Rheum. 2007;56:2640-51

21. Khan MA. Polymorphism of HLA-B27: 105 subtypes currently known. Curr Rheumatol Rep. 2013;15:362-7.

22. Robinson J, Halliwell JA, Hayhurst JD, Flicek P, Parham P, Marsh SG. The IPD and IMGT/HLA database: allele variant databases. Nucleic Acids Res. 2014;43:423-31.

23. Khan MA. An update on the genetic polymorphism of HLA-B*27 with 213 alleles encompassing 160 subtypes (and still counting). Curr Rheumatol Rep. 2017;19:9-15.

24. Khan MA. Update: the twenty subtypes of HLAB27. Curr Opin Rheumatol. 2000;12:235-8.

25. Akkoc N, Khan MA. HLA-B27 and ankylosing spondylitis. APLAR J Rheumatol. 2005;8:146-53.

26. Lopez de Castro JA, Alvarez I, Marcilla M, Paradela A, Ramos M, Sesma L et al. HLA-B27: a registry of constitutive peptide ligands. Tissue Antigens. 2004;63:424-45.

27. Khan MA. Update on spondyloarthropathies. Ann Intern Med. 2002;136:896-907.

28. Taurog JD. The mystery of HLA-B27: if it isn't one thing, it's another. Arthritis Rheum. 2007;56:2478-81.

29. Oguz FS, Ocal L, Diler AS, Ozkul H, Asicioglu F, Kasapoglu E, et al. HLA B-27 subtypes in Turkish patients with spondyloarthropathy and healthy controls. Dis Markers. 2004;20:309-12.

30. Acar M, Cora T, Tunc R, Acar H.HLA-B27 subtypes in Turkish patients with ankylosing spondylitis and healthy controls. Rheumatol Int. 2012;32:3103-5.

31. Birinci A, Bilgici A, Kuru O, Durupinar B. HLA-B27 polymorphism in Turkish patients with ankylosing spondylitis. Rheumatol Int. 2006;26:285-7.

32. Diyarbakir E, Eyerci N, Melikoglu M, Topcu A, Pirim I. HLA B27 subtype distribution among patients with ankylosing spondylitis in eastern Turkey. Genet Test Mol Biomarkers. 2012;16:456-8.

33. Varnavidou-Nicolaidou A, Karpasitou K, Georgiou D, Stylianou G, Kokkofitou A, Michalis C et al. HLA-B27 in the Greek Cypriot population: distribution of subtypes in patients with ankylosing spondylitis and other HLA-B27-related diseases. The possible protective role of $\mathrm{B} * 2707$. Hum Immunol. 2004;65:1451-4.

34. López-Larrea C, Sujirachato K, Mehra NK, Chiewsilp P, Isarangkura D, Kanga U et al. HLAB27 subtypes in Asian patients with ankylosing spondylitis. Evidence for new associations. Tissue Antigens. 1995;45:169-176.

35. Fiorillo MT, Meadows L., D'Amato M, Shabanowitz J, Hunt DF, Appella E et al. Susceptibility to ankylosing spondylitis correlates with the Cterminal residue of peptides presented by various HLA-B27 subtypes. Eur J Immunol. 1997;27:368-73

36. Miller SA, Dykes DD, Polesky HF. A simple salting out procedure for extracting DNA from human nucleated cells. Nucleic Acids Res. 1988;16:1215.

37. Bunce M. PCR-sequence-specific primer typing of HLA Class I and Class II alleles. In Methods in Molecular Biology: MHC Protocols (Eds SH Powis, RW Vaughan RW): 143-172. MHC Protocols, Totowa, NJ, Humana Press. 2003.

38. Maniatis T, Fritsch EF, Sambrook J. Molecular Cloning: a laboratory manuel. 1st Ed., New York: Cold Spring Harbor Laboratory. 1982.

39. Mittal KK, Mickey MR, Singal DP, Terasaki PI. Serotyping for homotransplantation. Refinement of microdroplet lymphocyte cytotoxicity test. Transplantation. 1968;8:913-27.

40. Dunky A, Neumüller J, Hübner C, Fischer GF, Bayer PM, Wagner E et al. HLA-B27 determination using serological methods. A comparison of enzyme immunoassay and a microlymphocytotoxic test with flow cytometry and a molecular biological assay. Rheumatol Int. 1996;16:95-100.

41. Coates E, Darke C. Routine HLA-B27 typing by flow cytometry: Differentiation of the products of HLA-B*2702, $B * 2705$ and $B * 2708$. Eur J Immunogenet. 1998;25:29-37.

42. Skalska U, Kozakiewicz A, Maslinski W and Jurkowska M. HLA-B27 detection - comparison of genetic sequence-based method and flow cytometry assay. Reumatologia. 2015;53:74-8. 
43. Levering $\mathrm{WH}$, Wind $\mathrm{H}$, Sintnicolaas $\mathrm{K}$, Hooijkaas $\mathrm{H}$, Gratama JW. Flow cytometric HLA-B27 screening: cross-reactivity patterns of commercially available anti-HLA-B27 monoclonal antibodies with other HLA-B antigens. Cytometry B Clin Cytom. 2003;54:28-38

44. Dominguez O, Coto E, Martinez-Naves E, Choo SY, Lopez-Larrea C. Molecular typing of HLA-B27 alleles. Immunogenetics. 1992;36:277-82.
45. Yang R, Zhang JH and Yuan GY. Establishment of an optimized PCR method using sequence-specific primers for screening multiple gene polymorphisms simultaneously. Mol Med Rep. 2013;7:201-4.

46. Cianga P, Zlei M, Rezus E, CiangaC. The flow cytometric labeling pattern in HLA-B27 detection may suggest cross reactivities. Rev Romana Med Lab. 2011;19:2-4. 